\title{
Ethos groceries and countercultural appetites: Consuming memory in Whole Foods' brand utopia
}

\author{
Michael Serazio \\ Fairfield University, mserazio@fairfield.edu
}

Follow this and additional works at: https://digitalcommons.fairfield.edu/communications-facultypubs Copyright 2011 Wiley-Blackwell.

This is a pre-print of an article accepted for publication in The Journal of Popular Culture (44, 1, 2011). The definitive version is available at www3.interscience.wiley.com

\section{Repository Citation}

Serazio, Michael, "Ethos groceries and countercultural appetites: Consuming memory in Whole Foods' brand utopia" (2011). Communication Faculty Publications. 11.

https://digitalcommons.fairfield.edu/communications-facultypubs/11

\section{Published Citation}

Serazio, Michael. 2011. Ethos groceries and countercultural appetites: Consuming memory in Whole Foods' brand utopia. The Journal of Popular Culture 44 (1) 158-177.

This item has been accepted for inclusion in DigitalCommons@Fairfield by an authorized administrator of DigitalCommons@Fairfield. It is brought to you by DigitalCommons@Fairfield with permission from the rightsholder(s) and is protected by copyright and/or related rights. You are free to use this item in any way that is permitted by the copyright and related rights legislation that applies to your use. For other uses, you need to obtain permission from the rights-holder(s) directly, unless additional rights are indicated by a Creative Commons license in the record and/or on the work itself. For more information, please contact digitalcommons@fairfield.edu. 
Running Head: ETHOS GROCERIES

Ethos Groceries and Countercultural Appetites:

A Case Study of Whole Foods

Contact:

Michael Serazio

Annenberg School for Communication

University of Pennsylvania

3620 Walnut St. Office 126

Philadelphia, PA 19104

Phone: 215.380 .8181

mserazio@asc.upenn.edu

Submitted to: Journal of Popular Culture (May 2007) 
Ethos Groceries and Countercultural Appetites: A Case Study of Whole Foods Introduction

“They're not selling food. They're selling life." - supermarket expert Phil Lempert on Whole Foods. (Horovitz B1)

To walk through a Whole Foods Market is to experience what some industry experts hail as nothing less than a revolution in supermarket shopping and grocery consumption. But Whole Foods' success represents something much more than a remarkable model for business growth. It is also a telling case study in how increasingly articulate values and identity have become grafted onto a shopping experience and consumer culture otherwise considered "more banal, more everyday and more routinized" than perhaps any other (Dickinson and Maugh 259). Groceries have certainly never been insulated from the same logics of branding that have grown to dominate the rest of consumer society since the turn of the 20th-century. Yet Whole Foods' expansion from niche margins to mainstream consciousness clearly emerges against the bland backdrop of the "conventional" grocery store experience - a vanilla experience embodied by venerable market leaders like Kroger, Albertsons and Safeway. More importantly, that emergence coincides with powerful shifts and demographic trends in American popular culture that concern ethical consumption, the collective memory of the $1960 \mathrm{~s}$, and the shopper's relationship to globalization.

This paper will argue that Whole Foods constructs a distinct and influential narrative within a consumer subculture (grocery shopping) that has long been short on branded lifestyle. The supermarket has traditionally been conceived quite literally as a "mass market" - a market for all - thereby watering down style and distinction to cater to 
the lowest common denominator; Whole Foods pursues niche, much in the way many other businesses and industries have, in recent decades, targeted smaller, more lucrative demographic slices. The narrative that is bought and sold daily at Whole Foods co-opts countercultural ideals and political stirrings aimed largely at the baby boomer bourgeois. Shoppers have long consumed "ethos shoes," "ethos cars," and "ethos liquor" - that is, products differentiated by brand aura and packaged in a specific cultural format. It would appear that Whole Foods is one of the first supermarkets to begin pushing "ethos groceries" - that dazzling panoply of foodstuffs steeped in ideology and marketed to a robust segment of American consumers. Ethos groceries may well represent the next stage of branded products - defined as capturing the moral character, spirit, or imagination of a culture which, in this case, seeks to be bourgeois, bohemian, and baby boomer all at once. Many companies have been able to weave common identity across related, cooperative product lines (take Apple, for example); the Whole Foods chain manages to weave competing products on its shelves into a larger, coherent narrative. This is a narrative that seeks to soothe the discomforts of aging and mortality, politics and history, and globalization's promise and perils. By analyzing several hundred articles about Whole Foods in the popular press, the marketing industry press and the grocery industry press, and by rhetorically deconstructing the material evidence at a Whole Foods store, I hope to illuminate this narrative and the ideology that girds it. ${ }^{1}$ In short, I hope to explain what appetite is really being fed by such ethos groceries.

Theoretical and Historical Prisms

As a useful point of departure, Don Slater synthesizes the romanticist critique that material culture lacks a sense of "authenticity" to the "natural" self: "Romanticism and 
the concept of culture argue that there are things larger than the individual - community, nation, race, nature, spirit, the ideal of art - which alone can produce those values that will render the individual authentic, real" (66). Both longings - for authenticity and the natural self - as well as the larger romanticist critique of modern life surface in the Whole Foods narrative, although, of course, it is further consumption - specified consumption through the store - that provides the cure. For the romantic, that organicism is reified with implications of "wholeness, naturalness and integration" (67). This set of ideals is explicitly interwoven into the fabric of a Whole Foods Market. By carving out and colonizing a space - physical and imaginary - for ethos groceries, Whole Foods imbues its food offerings with these larger themes of politics, culture and lifestyle; Whole Foods nurtures this consumer culture of food fetish through its soothing tale of wholeness.

Douglas B. Holt further advances a useful framework for understanding the role of what he terms "iconic brands" ("Jack Daniel's" 355). Brands reach iconic status when they become "prominent and enduring cultural symbols... [that] organize collective identities, as expressions of the major social axes such as class, gender, and race within a particular national discourse and beyond" (357). Brands acquire culturally-located power by expressing myths of identity; typically such expressions arise from "existing myth markets" that the brand parasitically latches onto (372). These brands achieve most notable success when they tap into particularly charged, colorfully distinct ideological undercurrents in society: Here Holt cites the "frontier myth" of Harley Davidson, the "Hobbesian sporting worlds" of Nike, and, of relevance to Whole Foods, the "sustainable development mythos" of Patagonia and Ben \& Jerry's (374). Holt also offers methodological advice on excavating such icons of popular consumption. To analyze 
brands as a form of expressive culture (the goal of these efforts), he advocates "a hermeneutic approach, locating the meaning and value of brand symbolism in a particular historic context" (359). This work aims to apply this kind of interpretive approach to the Whole Foods brand, locating ethos groceries within the context of a counterculture myth that largely - though certainly not exclusively - calls out to the aging baby boomer.

As Gary Cross argues in the thesis of his book on commercialism in 20th-century America: "Consumerism was the 'ism' that won - despite repeated attacks on it as a threat to folk and high culture, to 'true' community and individuality, and to the environment" (1). As later sections will demonstrate, Whole Foods, through co-optation, situates itself effectively to channel each of these attacking forces. Cross documents several of the cultural elements upon which Whole Foods would eventually capitalize in his review of 1960 s consumer developments and critiques. Indeed, few themes are more salient to understanding the grocery chain and its success than the counterculture movement of that era. In this period, environmentalism emerged with renewed zeal, as authors like Fairfield Osborn and Rachel Carson championed conservation and ecological responsibility. "A revolt against the conformity and 'materialism' of the suburban populuxe was associated with the bohemian or beatnik," and the hippie heyday of the late 1960s made good on that bohemian promise through familiar clichés of free love and drug culture (Cross 151). All of this was coupled with the political upheaval associated with the period's tumultuous civil rights, feminist and Vietnam War movements. Cross notes that this countercultural activism - which, to a large degree, later came to represent the baby boomer's 1960s narrative as a whole - initially took pride in an all-out rejection of "the system." Between 1965 and 1970, several thousand did "drop out" and form rural 
communes, while others formed food and craft co-ops - the seedlings of the Whole Foods philosophy. "This movement made a serious critique of the nutritional value of hyped and processed commercial foods" (165). In many ways, Whole Foods sustains this critique and, in turn, the critique sustains Whole Foods - its roots can be traced to a small natural foods co-op in Austin and, even today, its ethos grocery image reflects an implicit suspicion of the "hyped and processed" products of Tyson and ConAgra on sale at Albertsons and Kroger.

However, as Cross diagrams, these countercultural forces could not break free of consumerism entirely but rather deferred faith to other products within it: "The politics of style became just style, another market segment easily integrated into the merchandising system" (167). Even as the 1960s counterculture mocked the consumption practices of the middle and working classes, "the system" simply co-opted the rebellion. "Hip consumption was a substitute for new institutions, socially binding rituals, and, of course, serious political action" (167). Whole Foods can be read as an emporium of this substitution: simulating politics, cribbing communalism. Thomas Frank highlights how the advertising industry not only participated in, but helped precipitate this $1960 \mathrm{~s}$ consciousness that revered "groups that are believed to have been so transgressive and revolutionary" (6). It is that same consciousnesses - transgressive, revolutionary, tugging at myths from four decades ago - that Whole Foods cannibalizes so successfully. By Frank's reckoning - and echoing some of Cross's aforementioned themes - the "Establishment" flooded the marketplace with cultural products that it hoped would "buy off and absorb its opposition, emblems of dissent that were quickly translated into harmless consumer commodities, emptied of content, and sold to their very originators as 
substitutes for the real thing" (Frank 16). Whole Foods is, of course, neither the first nor the only "product" in the American marketplace to capitalize on counterculture commodity in this way. Yet Whole Foods may very well be the first and it is certainly the most successful and prominent to tap this vein as a grocery chain.

In that vein, Mike Featherstone's analysis of the "new middle classes" - many of whom are those same Whole Foods patrons who act as both "producers/disseminators and consumers/audiences for cultural goods" - might help clarify the relationship between the middle classes and bohemia within postmodern culture (35). Featherstone points out that the relationship partly stems from this baby boomer generation gaining higher education in greater numbers than any before it and, thus, cultivating the sensibilities and preferences that carry them through adult life. This group - "engaged in providing symbolic goods and services" through their professions, desirous of cultural capital in their consumption - is "fascinated by identity, presentation, appearance, lifestyle, and the endless quest for new experience" (44). Through ethos groceries, Whole Foods caters to their veneration of the ideal artistic and intellectual lifestyle.

Before directly engaging Whole Foods as text, one more popular social critic lends tremendous prescience to this undertaking. In his book on the demographic phenomenon of bourgeois bohemians, or "Bobos," David Brooks charts the merger of free-spirited, anti-establishment bohemians - whose countercultural roots include artists, intellectuals, hippies and Beatniks - with the bourgeois world of capitalism and material success. Similar to Featherstone's contention, this “educated class ethos," Brooks claims, is a "cultural consequence of the information age" (10). Moreover, the sort of Bobos who find themselves shopping at a place like Whole Foods hope to find ethos groceries 
that address the "anxieties of abundance;" "negotiate the shoals between their affluence and self-respect;" and "reconcile their success with their spirituality, their elite status with their egalitarian ideals" (40). It should be cautioned that that reconciliation remains, at best, an ostensible approximation; the promise of "moral confidence" in this consumer process is necessary in the sales pitch because of the abyss of brazen commoditization that lies beneath it. Brooks points to the organic items tally at a grocery chain similar to Whole Foods as a kind of "barometer of virtue" that's intended to provide customers with that "moral confidence" (58). In sum, this romanticist bohemianism, now afforded the luxuries of bourgeois spending, prefers consumption that reflects "a different set of words, which exemplify a different temper and spirit: authentic, natural, warm, rustic, simple, honest, organic, comfortable, craftsmanlike, unique, sensible, sincere" (83). With this, Brooks has concisely codified the evocative yearnings that envelop Whole Foods' ethos groceries. This work shall now unpack those codes and yearnings that resonate in the company's narrative.

\section{Press Mythology}

Although it may seem antithetical to a company which outwardly embraces such a “grassroots" identity, Whole Foods' ethos can be interpreted in one way as image defined from the top down. As such, the figure of CEO and co-founder John Mackey can be read as the embodiment of the company - and, more so, he serves to represent his upscale counterculture consumer in bodily form. In Mackey's representations to the public through press accounts, he projects an attainable image for identification; a face for the brand that is one with the bourgeois boomer. Early in the brand's emergence, he appears in a Forbes magazine feature "looking like one of the Beatles circa their Sgt. Peppers 
Lonely Hearts Club Band album" (Mack 112). Readers learn that he arrives for work in hiking shorts; has interests in yoga, meditation, and scuba diving; dropped out of college in Austin a few credits shy of a philosophy degree; and "just hung out" for a few years living in a vegetarian co-op as a self-described "hippie." On the Whole Foods official website, a company mythology details Mackey "bathing in the Hobart dishwasher" when forced to live out of his first store. The characterization remains essential vis-à-vis its deliberate positioning of the consumer in a similar specific place. This is not the figure of the button-up, bottom-line boardroom raider we might conventionally associate with executive leadership - his hippie credentials serve as critical credibility. As the story goes, in the late 1970s, Mackey opened up what later became the first Whole Foods Market and "stumbled" upon a robust, escalating market for organic foods. This "stumble" serves to soothe baby boomer bohemian anxiety over living through a bull market run: Financial success happened upon Mackey (and his customers who can afford to shop there) without need of rapacious capitalist instinct and certainly without having to officially "sell out" 1960s ideals. In that, he represents a comforting role model to the Bobo who seeks both luxury and principle. And throughout the years of coverage, Mackey retains the reliable rhetoric of a bohemian romantic: He tells Forbes, "We're trying to build a company based on trust and love" (Mack 112). To Business Week he declares, "Wall Street isn't going to corrupt Whole Foods Market... We're going to purify Wall Street” (Zellner 94). In this, he strikes the rebel pose, ostentatiously fastidious about his cultural credentials (transgressive, revolutionary) in the face of a vaguely-defined, encroaching Establishment. 
As Business Week claims: "You can even find traces of the summer of ' 67 in the way he runs his $\$ 1.4$ billion health-food empire" (Zellner 79). We are made to believe that Mackey has somehow reconciled the conflicting values of the "Summer of Love" with capitalist principles and aggressive chain expansion - that, by grafting the puristminded hippie ideal onto Whole Foods Fortune 500 image, he has been able to nurture one of the "hottest" companies in retailing (McGinn 36). ${ }^{2}$ Company stock has gone up 25-fold since a 1992 public offering and the chain has bought up competing natural-foods retailers nationwide; it has plans to double its stores (168 currently) by 2010 and quadruple its revenue ( $\$ 3.9$ billion) by 2012 . Fusing countercultural imagery with bourgeois prices steep enough to command a "Whole Paycheck" nickname and reputation, Brandweek gushed: "All the trends of healthful eating and politically correct notions of oneness with the earth and global villageship have aligned to make an oddball hippie tradition the slickest upscale trip of the "90s" (Spethmann 56). In a sense, Whole Foods has become the Counterculture Establishment - so much so that, Brandweek adds, "Mom \& Pop natural food stores get nervous when Whole Foods comes to town. Its size means more selection and better prices, stiff competition for tiny specialty store." Thus, the more markets that America's leading natural and organic foods retailer conquers and the more it assumes the position of counterculture Goliath, the more important it is for the brand to maintain its ethos groceries aura and for Mackey in particular to retain his “hippie" underdog image. ${ }^{3}$

The popular and marketing literature on Whole Foods draws an intriguing picture of its consumer construction. The Whole Foods shopper - often described as "highly 
educated, affluent 35- to 55-year-olds" - is product of the same two unique cultural forces that engenders Brooks' Bobo phenomenon:

This could only be the politically-correct 90s, where the doctrines of Harvard MBAism don't clash with the tenets of vegetarianism. In fact, our hyperkinetic business culture has begun to weave two erstwhile opposite ends of the enterprise spectrum into a single, powerful profit model. Natural foods retailing, long grocery marketing's flower-child-populated, negligible backwater, has bloomed into the fastest growing segment of the supermarket industry. (Spethmann 18) Whole Foods' success is frequently constructed as a kind of demographic convergence in this regard: "Once a magnet for the Birkenstock crowd, Whole Foods is now all the rage in affluent cities and suburbs" (Murane). Partly this seems a product of changing class tastes; it also registers as a function of aging consumers and their move toward healthy lifestyles: "Birkenstock-wearing hippie types aren't the only ones chowing down on hard-core health food anymore. Now aging baby boomers worried about that dreaded cholesterol count are just as likely to eat it up" (Miller 2). According to industry analysts, natural food companies no longer have to battle the "kooky or weird" stigma that used to cling to their image: "Organic used to mean bohemian, and it had these hippie connotations, but it's so much more prevalent now" one industry expert notes (Miller 1). The success of Whole Foods ethos groceries is repeatedly framed in terms of a demographic shift that finds mainstream, "yuppie” appeal for previously niche, "hippie" products. As an example, "Peace Cereal" Vanilla Nut Rainforest Crisp, a Whole Foods "ethos" brand that donates 10 percent of profits to rainforest preservation, shows its mass market potential when it appears at conventional grocery stores like Kroger and 
Safeway. ${ }^{4}$ Mackey himself confides that Whole Foods is "evolving beyond niche status" and "tipping into mainstream consciousness" (McGinn 36).

In reality, Whole Foods has been mainstreaming the margins of this romanticist bohemia - co-opting countercultural appetites and imagery for those who now find themselves in a higher tax bracket. To read press accounts, Whole Foods success is a confluence of social movement factors: hippie iconography; environmental awareness; dietary health; and the globalization of ethos grocery palates. The chain seeks to cater to an upscale counterculture, offering, as one psychology expert opines, "a psychological absolution of our excesses" by way of milk, bread, fruit and other groceries (Horovitz B1). Those excesses are seen to exist at multiple levels: On one hand, rich, luxurious foods wrapped in an ethos of "healthiness" allow the consumer to overcome the nutrition fact negatives. But, even more so, rich, luxurious foods wrapped in an ethos of ethical shopping offer the consumer the chance to be simultaneously radical and bourgeois; to be absolved of moral ambivalence about personal wealth and elite status. They give the shopper the chance to buy values through grocery products that never had such descriptive identity before: leftist values; 1960s values; environmental values; spiritual values; antiwar values; pluralistic values; and even anti-consumerist values are all for sale on the shelf at Whole Foods. In a recent conference call with shareholders, Mackey declared simply, "We are a lifestyle brand" (Hogan). The details of that "lifestyle" are hopefully becoming clear through its popular representation thus far; now I will take closer direct examination of that environment and, more importantly, the ethos groceries that exist within it. 


\section{Material Narrative}

Greg Dickinson and Casey M. Maugh offer not only a useful methodological template for approaching the grocery store as text - that is, a site of cultural meaning available to be read - they also lay out a convincing rationale:

Grocery stores, supermarkets, super-shopping centers, health-food stores, wholefood markets, and co-ops provide more than food, they materialize consumer culture in tidy, colorful packages. Further, they are material and visual sites in which individuals directly negotiate their relations with globalized consumer culture. (259)

That is, through a gallon of milk or a head of lettuce, the consumer interacts, both in real and imagined terms, with the process of globalization. Moreover, they argue, the grocery store functions as a critical nexus for viewing the intersection of global transformations with localized objects. Dickinson and Maugh specifically focus on a Wild Oats store - part of the upscale, organic chain considered Whole Foods' main competitor. They locate much of their analysis in the context of globalization and consumption, arguing that, "Wild Oats responds to the abstractions and discomforts of globalized postmodern consumer culture with a rhetoric of connection that draws on images of locality and nature, and asserts a particular form of community" (260). This section will build on these conclusions and advance the countercultural features highlighted to this point as part of the ethos grocer's appeal - this "community" they discuss is asserted in a distinctly social and political way.

In what might be termed a kind of material ethnography, Dickinson and Maugh start their tour through Wild Oats by considering how the name itself anchors the store in 
nature, in wilderness, in the untamed. This, one might add, attempts to contrast the conquered, subordinate image of earth that the "conventional" grocery store seems to traditionally represent - the sterile aisles, the mechanized replication of stocked items, in one case, the very word itself, "Safeway." "Whole Foods," too, merits such inquisition: Wholeness plays upon spiritual values and holistic healing - it seeks to repair the dislocation of processed, manufactured grocery parts and returns the consumer to a premodern nostalgia for communal eating, of knowing and sharing in the whole process of the agrarian food harvest. In similar contrast to "the seeming ahistoricity and placelessness" of Kroger and Albertsons, Whole Foods rhetorically roots the shopper in this natural utopia (265). Dickinson and Maugh further note the contrast of Wild Oats' "progressive vision of globalization" with the "colonizing force of corporations like McDonalds" (267). Whole Foods, too, seeks to promise better living for both producers and consumers around the world; it hopes to flatten the hierarchy of perceived inequality and exploitation that so torments the ethically minded consumer, the guilt-ridden luxury shopper. And, more particularly, it soothes the aging, bourgeois baby boomer by recalling and packaging the hip, resistant values of 1960s bohemia.

Cross explains, “The 'philosophy' of consumerism was embedded in words and images of the ad agency and display designer, who welded human physical needs, impulses, and fantasies to packaged goods" (5). This principle emerges as especially critical in the realm of Whole Foods' ethos groceries, given the following: The organic food industry averaged 20 percent growth over the course of the 1990 s and, by 2005 , tallied $\$ 20$ billion in sales, with 60 percent of consumers claiming they would be willing 
to try organic foods (Grimm 66). Yet even as category awareness grew to new heights, brand recognition remained almost non-existent. One industry expert noted:

The majority of consumers who buy organic products are not brand oriented. They are interested in organics as a way of life. So we're seeing more manufacturers getting a sense of how to market to what we call this "lifestyle branding," instead of talking about their product. That's what the customers in this category are buying. (Janoff)

This is partly what makes "shelf presence" so absolutely essential to the aspiring organic brand and what makes the grocery store text a good arena to locate that transaction of "needs, impulses and fantasies" as expressed to the consumer. Moreover, what makes this space so intriguing is that, dissimilar to Safeway or Albertsons' shelves, with their products' competing, less articulate narratives, the products on a Whole Foods shelf largely offer cooperative narratives toward coherent arc. Whole Foods blends countless SKUs into a thematic whole - an oneness, a "wholeness" achieved by marketing to this industrial conception of audience. To be certain, this review of a sample of Whole Foods' ethos groceries will not be exhaustive - there is little space or utility in journeying through the thousands and thousands of micro-rhetorics that companies attempt to graft onto their products. However, this will capture the macrorhetorics in operation, many of which illuminate themes already mentioned. What stories are told in the signs, labels, and products? What ultimate brand message about audience is constructed? And why does it matter?

Dickinson and Maugh declare of their Wild Oats visit: "Nearly every package, in some way or another, proclaims the naturalness of the product inside" (268). This is, of 
course, the most dominant pattern observed at Whole Foods as well. "Without this maneuver," Dickinson and Maugh add, "the bag of chips at Wild Oats would seem to be more or less the same as a bag of Doritos." As but a few examples, one finds “Earthbound Farm" organic salad packs; "Mother Earth" organic mushrooms; "Nature's Choice" multigrain cereal bars one shelf over from "Nature's Path" instant hot cereal; and, drilling the message home in a redundant climax, "Natural by Nature" organic milk. The store relentlessly locates the consumer through perceived "back to nature" preferences and organic redemption. Near the entrance, a large sign triumphantly tallies “193 organic items today" - that "barometer of virtue," as Brooks labeled it. Nature registers not only through explicit reference, but evocative forms of pre-modern nostalgia. "Organic Natural Brew Handcrafted Ginseng Cola" might be a long label, but the "handcrafted" portion exudes a craftsmanship glow against the assembly line food machines of modernity. "Naked Juice" rhetorically retreats the consumer even further back to a Garden of Eden paradise. In sum, this can be read as a declaration against modernity; a triumph of agrarian ambience; the sinless, guiltless pre-industrial.

Not surprisingly, the environmentalist ethic weaves itself especially prominently throughout the store. "Seventh Generation" recycled paper napkins quote the Great Law of the Iroquois Confederacy: "In our every deliberation we must consider the impact of our decisions on the next generation." The "Endangered Species Chocolate Company" proudly announces that it donates 10 percent of chocolate bar sales to wildlife protection. The "EnviroKidz" organic cereal brand highlights that one percent of sales will be donated to similar causes, adding, "Thanks to all these waffles and bowls of cereal you ate, we have donated significantly to species conservation." Ethical shopping is neither 
new nor unique to Whole Foods, but these kinds of ethos groceries promise the ultimate counterculture consolation: consumption toward conservation. While consumption has long stood in opposition to conservation - indeed, it has variously functioned as a threat to conservation - ethos groceries satisfy both urges and rectify their seeming incompatibility as well as the bohemian's unease with bourgeois-worthy spending habits. These sorts of products are presented to pacify counterculture fears; they mold a narrative that comports with the ideals of Fairfield Osborn and Rachel Carson, but still allow for luxurious indulgence.

In addition to environmentalism, other political and religious causes rise to the foreground through Whole Foods ethos groceries. "Kind" brand fruit and nut bars donate five percent of profits to a PeaceWorks foundation that fosters peace in the Middle East. The Merry Hempsters vegan hemp lip balm plays coyly to marijuana legalization sympathies. In a particularly insightful confluence of religion and politics, "Peace Cereal" Raspberry Ginger Lowfat Crisp, founded by Yogi Bhajan, donates 10 percent of proceeds toward sponsoring an International Peace Prayer Day in the Jemez Mountains of New Mexico. Whole Foods' ethos groceries are also frequently infused with spiritual overtones - a pluralistic, often Eastern-centric religious vision. "ZenSoy" pudding sits in the dairy aisle; "Feng Shui" rice crackers proffer "a perfect balance" through snacking; and the "Dagoba Organic Chocolate Company" helps define "dagoba" as the "temple of the gods" and "therobroma" as the "food of the gods," adding, "There is an art to the alchemy of chocolate; an art which we explore with ingenuity and mystery." Whole Foods, by way of Dagoba, has taken the humble chocolate bar from Hershey's and placed it at the center of a kind of polytheistic rite, infusing it with curiously specific religious 
identity. But it is not only food that comes draped in religious overtones - the spiritual dimension of consumption is extended to other products and categories as well. Whole Foods is, after all, an all-purpose lifestyle brand. Near the front of the store, Buddha statues sit near "Tibetan Sacred Journey" incense; "Lucky Karma" wrist beads are sold, promising "overflowing miracles" and "everything you desire can come your way;" and there are, naturally, yoga bricks, Pilates mats, and meditation DVDs. In the frozen foods section, in the form of "Ezekiel 4:9" sesame sprouted grain burger buns, a JudeoChristian reference slips in: "This Biblical Brand is truly the stuff of life." In effect, spiritual wholeness is made available by way of soy pudding, chocolate bars and burger buns.

Beyond the embedded values of these ethos groceries, there is an implicit countercultural narrative that speaks quite clearly to the baby boomer demographic. "Imagine" brand vegetable cooking stock conjures up John Lennon undertones, and Linda McCartney's macaroni-and-cheese further engages the Beatles iconography. Taking a closer look at the "Back to Nature" crispy oatmeal cookies package, one discovers a redolent tale: "It was 1960, in Pasadena, California when we decided the best way to move forward was to go back. Back to simplicity. Back to goodness. Back to what was real. Back to honest ingredients, unadulterated tastes, intriguing textures." One shelf over, "Nature's Path" lemon poppy cookies packaging echoes a similar "back in the seventies" narrative. These products make clear the warmly evocative memorializing that takes place through ethos groceries; these oatmeal and lemon poppy cookies offer the baby boomer a chance to feast not only on snack foods but 1960s reminiscence. The era serves as brand, baiting the consumer to dine upon remembered 
ideals and that halcyon collective memory. The promise, the hope, the idealism of Woodstock lives on - in a purchase of Ben and Jerry's "Cherry Garcia" ice cream. In their analysis, Dickinson and Maugh focus much attention upon the anxieties and reassurances of globalization apparent at Wild Oats, and Whole Foods contributes to many of those conclusions as well. Strolling through the store, one cannot help but be struck by the sense of imperial eating: The whole world is available for the consumer's plate. Indeed, it shows how the American shopper sees the world through the products on a grocery shelf. In the bulk aisle alone, one can stock up on Turkish apricots, whole wheat couscous, and Himalayan red rice; further over, a single aisle contains another global pastiche of "Thai Kitchen" pad Thai, "Kitchens of India" lamb curry, "Goya" brand tamarind juice, and Japanese panko (bread crumb) flakes. Domestically, certain resonant states like Oregon and Vermont, as well as cities like Austin and Santa Cruz, acquire a halo of hippie reverence; internationally, A-list tourist destinations get namechecked, as with Pacifica's "Zanzibar Cinnamon Almond," "Madagascar Spice," "Bali Lime Papaya," and "Brazilian Mango Grapefruit" soap options. These are shorthand siren songs for the well-traveled, affluent Whole Foods patron. Through fusion flavors, these and other products project a multicultural utopia; their well-proportioned representation on the shelves is the culinary equivalent of affirmative action. "Kettle" brand potato chips alone offer a paralyzing pageantry of choice: Will it be New York cheddar, spicy Thai, honey Dijon, Tuscan three cheese or chipotle chili barbecue flavor? Featherstone might help clarify the logic of these expanding global options:

[The interest of] cultural specialists within the new middle class... may be less in the attempt to impose a particular style on consumer audiences and more in terms 
of a general interest in the full range of styles from different cultures, civilizations and traditions which they can play and replay. (109)

Yet despite the material wealth that affords this range of global tastes and pleasures, there remains a dissonant concern about the globalized means of production and the neoliberal economic systems that govern those processes. Thus, as with Wild Oats, Whole Foods ethos groceries must also make the argument that "rather than colonizing native others, their practices enhance the lives and communities of workers" (Dickinson and Maugh 267). The Allegro "handcrafted" coffee brand available at Whole Foods provides good insight into this. Despite fetishizing colonized locales like Sumatra, Kenya, Kona, and Guatemala with these names on the labels, the guarantee of Allegro's "fair trade" is stamped as a barometer of absolution; thusly, in a marketplace profoundly impacted by globalization, the counterculture consumer can conduct guiltless imperial eating. One glance at "World of Good" journals handmade by Bali artisans offers the ultimate redemption: The families of the Indonesian small village of Tegallalang turn nature's "litter into art," by collecting leaves, twigs and dried fruit from their garden to make the cover of the journals. This is wholesome production and wholesome consumption par excellence. If the commodity fetish seeks to obscure the means of production from the end-point consumer, to psychologically remove "work" from the product equation, Whole Foods is taking its consumer by the hand and lifting back the curtain to reveal, indeed, moral consolation with the process. Moreover, this effort dovetails with the store's emphasis on the "natural" - fulfilling both the problem of alienation from agrarian roots (the Tegallalang villager's connectedness with nature is 
bestowed upon the Whole Foods shopper through purchase) as well the problem of perceived exploitation of supply-chain workers.

As the Whole Foods shopper pushes his or her cart to the checkout line, a bevy of magazines offer final confirmation that contrasts the tone of the store - and the consumer with it - with the "mainstream" supermarket: Adbusters for the anti-consumer consumer; Shambala Sun for the burgeoning Buddhist; and Punk Planet for suburban punk rocker. The luxury-priced products in the cart guide an environmentally conscious, politically correct, spiritually pluralistic, 1960s nostalgic, ethically consuming shopper. Like never before, groceries can now serve as the vehicle for counterculture ethos; they can feed appetites that go well beyond mere food.

\section{Conclusion}

As Whole Foods has grown over two decades of existence - thereby reinventing the grocery purchase as identity and narrative and colonizing imaginations through previously undefined products - it has equally helped reinvent the grocery store space as a medium. James Mayo's work on the history and evolution of the supermarket offers a sweeping backdrop against which Whole Foods' approach re-imagines. At a time when supermarkets are "facing an identity crisis," Whole Foods is helping redefine and reshape the industry landscape through its innovations (Warner 1). The stores attempt to "exude a sort of opulent hipness" in contrast to what CEO Mackey describes as "sterile and boring" conventional grocery stores (Sechler B2E). This is achieved through novelties like adding a book department, offering massages after the checkout line, having live musicians strum acoustic sets and opening a day spa in its Dallas outlet (Abramowitz A03). One store has even offered a "single's night" (Saulny C01). Whole Foods 
attempts to "feed the 'linger longer' effect... establishing its stores as community meeting places" and breaking with the conventional grocery store's "mass market" anomie (Spethmann 18). Whole Foods has thereby broadened the definition and function of the supermarket; it has tried to implicate itself into more and more activities of the targeted consumer's lifestyle. A quick look at their new \$15 million, 80,000-square-foot Austin flagship reveals the possibility of a pleasure dome in full; a Willie Wonka-worthy spectacle of "shopping as showtime" that, again in the words of Mackey, pioneers "a new lifestyle that synthesizes health and pleasure":

The premise is simple: make grocery shopping fun. Just bring your platinum card for a visit to: Candy Island, where you can dip a fresh strawberry in a flowing, chocolate river for \$1.59 each. Lamar Street Greens, where you can sit among the organic produce and have a salad handmade for you to enjoy with a glass of Chardonnay... Pleasure is woven into every crevice of the new flagship store. Such as the guy who hawks fresh hot doughnuts - with no artificial ingredients, of course. A walk-in beer cooler (bring your mittens) and 800 kinds of beer. And 14 pastry chefs - any of whom will be happy to whip up a baked Alaska on the spot... The lighting for the produce is the kind used in art galleries. The music is classical. Walk by the hot nut section and special fans waft that tummy-teasing smell of roasting nuts your way. (Horovitz B1)

This represents not only the pleasure apotheosis of the Whole Foods experience titillating every sense at bourgeois prices - but this may presage the luxurious future of the counterculture imagination. It is the grocery store functioning as a kind of adult playland - a posh, almost lurid indulgence of food flavor, texture, and scent. "We're not 
Holy Foods," cautions a company co-president, “we're Whole Foods” (Horovitz B1).

And, yet, the brand has indeed sought and perhaps achieved a holiness of consumption

through the themes identified in this research. It tries to appear as the utopia of ethos

groceries, the temple of food on one's path to consumption nirvana.

As has been shown here, Whole Foods strikes a delicate and telling balance in

addressing its U.S. consumer. It negotiates the forces of globalization and offers a prism through which to view the rest of the world. It orchestrates two conflicting impulses one of luxury, of indulgence, what Theodore Veblen called "conspicuous consumption" on the way to Pierre Bourdieu's “cultural capital." But it must simultaneously engage with virtuous asceticism and morally upright consumption; it must function as both pleasure and probity. As the kind of "identity myth" that Holt describes, Whole Foods exudes distinct iconography that captures a countercultural imagination and wraps it in opulence. As a future of grocery store consumption, it may herald a new world of expectations and appetites.

\footnotetext{
${ }^{1}$ From the popular press, a Factiva search for articles containing either the terms "Whole Foods" or "Trader Joes," a relevant competitor, in Barron's, BusinessWeek, Dow Jones News Service, Forbes, Fortune, The Los Angeles Times, Newsweek, The New York Times, The Wall Street Journal, The Washington Post, Time and U.S.A. Today retrieved 357 articles for all dates up until September 2006. From the marketing industry press, a Lexis-Nexis search for articles in Advertising Age, Advertising Age Creativity, AdWeek, American Demographics, Brand Strategy, Brandweek, Fast Company, Marketing News and Marketing Management retrieved 145 articles for the same terms and search period. From the grocery industry press, an EBSCO search in Progressive Grocer retrieved 254 articles. (Articles concerning only "Trader Joes" were later discarded as the study came to focus upon "Whole Foods" alone.) This sample, whittled to 160 of the more extensive, relevant and illuminating documents, was then textually analyzed and categorized for emergent themes. For the material narrative, two visits lasting several hours each were made to a Whole Foods store in a major metropolitan city on the East Coast. Each product label was read, noted, analyzed and categorized according to the same themes.

${ }^{2}$ Several articles note, however, that Mackey remains fiercely anti-union and libertarian in his business acumen, which has led to critical coverage in leftist-minded magazines like The Nation. Because of this, the United Food and Commercial Workers union claims, "Whole Foods touchy-feely image is a "sham"” (Abramowitz A03).

${ }^{3}$ Regarding Whole Foods domination, one article even notes that some have jokingly nicknamed it "Whole-mart" in a nod to Sam Walton's global Goliath - the ironic antithesis of Whole Foods' pursued image.
} 


\footnotetext{
${ }^{4}$ Mainstream grocery stores are increasingly feeling the pressure to respond to Whole Foods "lifestyle" push. For example, the chief marketing officer for Safeway tells Advertising Age, "We are moving from the traditional price/item advertising, which the norm for the supermarket industry, to a more brandfocused identity" (Frazier 4).

${ }^{5}$ Interestingly enough, Whole Foods had on display Frito-Lay's own venture into the organic category with a seeming oxymoron: "all-natural Doritos." Pepsi-Cola, Advertising Age reports, is also getting into the act: "To compete with the homespun, lifestyle-oriented companies that appeal to the Whole Foods consumer, Pepsi is creating new startup brands for the chain that bear no telltale trace of their corporate lineage" (Thompson 3).
}

\section{Works cited}

Abramowitz, Michael. “Berkeley’s New Age Shoppers Confront Old-Time Unionism in Organic Checkout Line.” The Washington Post 19 Feb. 1992: A03-. Factiva. 30

Nov. $2006<$ http://www.factiva.com>

Brooks, David. Bobos in Paradise: The New Upper Class and How They Got There. New York: Simon \& Schuster, 2000.

Cross, Gary. An All-Consuming Century: Why Commercialism Won in Modern America. New York: Columbia University Press, 2000.

Dickinson, Greg, and Casey M. Maugh. "Placing Visual Rhetoric: Finding Material Comfort in Wild Oats Market.” Defining Visual Rhetorics. Eds. Charles A. Hill and Marguerite Helmers. Mahwah, NJ: Lawrence Erlbaum Associates, 2004. 25976.

Featherstone, Mike. Consumer Culture and Postmodernism. London: Sage, 1991.

Frank, Thomas. The Conquest of Cool: Business Culture, Counterculture and the Rise of Hip Consumerism. Chicago: University of Chicago Press, 1997.

Frazier, Mya. "Priceless: Safeway Takes a Risk with a \$100M Brand-Focused Effort." Advertising Age 11 Apr. 2005: 4. Ebsco. 30 Nov. 2006 <http://www.ebsco.com> 
Grimm, Matthew. "Veggie Delight.” American Demographics Aug. 2000: 66-. LexisNexis. 30 Nov. $2006<$ http://web.lexis-nexis.com>

Hogan, Marc. “Whole Foods: A Little Too Rich?” BusinessWeek Online 21 July 2006. Factiva. 30 Nov. $2006<$ http://www.factiva.com>

Holt, Douglas B. How Brands Become Icons: The Principles of Cultural Branding. Cambridge, MA: Harvard Business School Press, 2004.

---. "Introduction: Toward a Sociology of Branding." Journal of Consumer Culture 6.3 (2006): 299-302.

---. “Jack Daniel's America: Iconic Brands as Ideological Parasites and Proselytizers." Journal of Consumer Culture 6.3 (2006): 355-377.

Horovitz, Bruce. "A Whole New Ballgame in Grocery Shopping.” U.S.A. Today 9 Mar. 2005: B1-. Factiva. 30 Nov. $2006<$ http://www.factiva.com>

Janoff, Barry. "Food Marketing." Brandweek 30 Apr. 2001. Lexis-Nexis. 30 Nov. 2006 $<$ http://web.lexis-nexis.com>

Mack, Toni. “Good Food, Great Margins.” Forbes 17 Oct. 1988: 112-. Factiva. 30 Nov. $2006<$ http://www.factiva.com>

Mayo, James M. The American Grocery Store: The Business Evolution of an Architectural Space. Westport, CT: Greenwood Press, 1990.

McGinn, Daniel. “The Green Machine.” Newsweek, 21 Mar. 2005: 36-. Factiva. 30 Nov. $2006<$ http://www.factiva.com>

Miller, Cyndee. “Challenge to Fat-Free.” Marketing News 21 Oct. 1996: 1-. Lexis-Nexis. 30 Nov. 2006 <http://web.lexis-nexis.com> 
Miller, Cyndee. “Health Food Sheds 'Hippie' Image.” Marketing News 14 Sept. 1992: 2-. Lexis-Nexis. 30 Nov. $2006<$ http://web.lexis-nexis.com>

Murane, Peter. “Top of Mind: My Grocery Store is Becoming My 7-11.” Brandweek 5 July 2005. Lexis-Nexis. 30 Nov. $2006<$ http://web.lexis-nexis.com>

Saulny, Susan. "In the Market?” The Washington Post, 21 June 1997: C01-. Factiva. 30 Nov. $2006<$ http://www.factiva.com>

Sechler, Bob. "Whole Foods Picks Up the Pace of Its Expansion." The Wall Street Journal 29 Sept. 2004: B2E-. Factiva. 30 Nov. $2006<$ http://www.factiva.com> Spethmann, Betsy. "Marketers of the Year '94.” Brandweek 14 Nov. 1994: 56-. LexisNexis. 30 Nov. $2006<$ http://web.lexis-nexis.com>

---. “Nature's Bounty.” Brandweek 6 Sept. 1993: 18-. Lexis-Nexis. 30 Nov. 2006 $<$ http://web.lexis-nexis.com>

Slater, Don. Consumer Culture and Modernity. Cambridge: Polity Press, 1997.

Thompson, Stephanie. "Pepsi Dons Disguise in Attempt to Seduce the Whole Foods Devotees." Advertising Age 6 Nov. 2006: 3-. Ebsco. 30 Nov. 2006 <http://www.ebsco.com>

Warner, Melanie. "Stores are Losing Shoppers to Specialty Chains and Discount Giants." The New York Times 6 Oct. 2005: 1-. Factiva. 30 Nov. 2006 $<$ http://www.factiva.com>

Zellner, Wendy. “Peace, Love, and the Bottom Line.” BusinessWeek, 7 Dec. 1998: 79-. Factiva. 30 Nov. $2006<$ http://www.factiva.com>

---. "Whole Foods Market: Moving Tofu into the Mainstream.” BusinessWeek 25 May 1992: 94-. Factiva. 30 Nov. $2006<$ http://www.factiva.com> 
Ethos Groceries 